\title{
CAMA
}

Centre for Applied Macroeconomic Analysis

\section{Renewable Energy Projections for Climate Change Mitigation: An Analysis of Uncertainty and Errors}

\section{CAMA Working Paper 74/2017 November 2017}

M. Indra al Irsyada

School of Earth and Environmental Sciences, University of Queensland

\section{Anthony Halog}

School of Earth and Environmental Sciences, University of Queensland

\section{Rabindra Nepal}

Centre for Applied Macroeconomic Analysis, ANU

\begin{abstract}
Failures of countries in setting and achieving renewable energy targets are prevalent, raising uncertainty about the overall contribution of renewable energy to global emission reductions. Lack of policy and incorrect modelling analysis are among the sources of the failures. Thus understanding these two sources is crucial to improve confidence about renewables. We assess errors in the projections of renewable energy capacity and production in the United States and European Union countries, which have high commitments to green energy supply. Our results show that solar energy has the lowest uncertainty due to having the most achievable projections of capacity and production. On the other hand, other renewables may entail attractive policies, and further research is needed related to advancing reliable technology and accurate weather predictions. Our findings also provide ranges of projection uncertainty of six renewable energy technologies and, at the same time, draw attention to ways to rectify the dominant errors in the renewable energy projections.
\end{abstract}




\title{
Keywords
}

Projection error, commitment, technical issues, modeling and policy

\author{
JEL Classification
}

\section{Address for correspondence:}

(E) cama.admin@anu.edu.au

ISSN 2206-0332

The Centre for Applied Macroeconomic Analysis in the Crawford School of Public Policy has been established to build strong links between professional macroeconomists. It provides a forum for quality macroeconomic research and discussion of policy issues between academia, government and the private sector.

The Crawford School of Public Policy is the Australian National University's public policy school, serving and influencing Australia, Asia and the Pacific through advanced policy research, graduate and executive education, and policy impact. 


\title{
Renewable Energy Projections for Climate Change Mitigation: An Analysis of Uncertainty and Errors
}

\author{
M. Indra al Irsyad ${ }^{\mathrm{a}, 1}$, Anthony Haloga, Rabindra Nepal ${ }^{\mathrm{b}}$ \\ ${ }^{a}$ School of Earth and Environmental Sciences, University of Queensland, Queensland - Australia \\ ${ }^{\mathrm{b}}$ Centre for Applied Macroeconomic Analysis, Australian National University, Australia
}

\begin{abstract}
Failures of countries in setting and achieving renewable energy targets are prevalent, raising uncertainty about the overall contribution of renewable energy to global emission reductions. Lack of policy and incorrect modelling analysis are among the sources of the failures. Thus understanding these two sources is crucial to improve confidence about renewables. We assess errors in the projections of renewable energy capacity and production in the United States and European Union countries, which have high commitments to green energy supply. Our results show that solar energy has the lowest uncertainty due to having the most achievable projections of capacity and production. On the other hand, other renewables may entail attractive policies, and further research is needed related to advancing reliable technology and accurate weather predictions. Our findings also provide ranges of projection uncertainty of six renewable energy technologies and, at the same time, draw attention to ways to rectify the dominant errors in the renewable energy projections.
\end{abstract}

Keywords: Projection error, commitment, technical issues, modeling and policy

\section{Introduction}

Increasing energy demand and the ongoing global push towards decarbonization to mitigate adverse impacts of climate change, have led to renewable energy intensification to stabilize emissions in the energy sector (Dulal et al., 2013; Luderer et al., 2014). At least 133 countries have stated their renewable energy targets globally (REN21, 2015). However, the development of renewables faces more challenges compared to fossil-based sources. One of the challenges is the need for higher upfront costs as a lower life cycle supply cost cannot be guaranteed due to the intermittent nature of supply, technology reliability, and the mismatched supply period to the demand (Brouwer et al., 2014; Byrnes et al., 2013; Dulal et al., 2013; Masini and Menichetti, 2012; Tasri and Susilawati, 2014; Yan and Saha, 2012; Zyadin et al., 2014). The literature also argues that utilization of renewables may potentially reduce national gross domestic product (GDP) and export and welfare in the long-term, as opposed to other clean energy options (Bhattacharya et al., 2016; Dannenberg et al., 2008).

Setting renewable energy targets is usually based on renewable energy projections. Thus, we use the target and projection terms interchangeably in this article. A successfully implemented projection

\footnotetext{
${ }^{1}$ Corresponding author at: School of Earth and Environmental Science, University of Queensland, Queensland Australia; R\&D Centre for Renewable Energy, Electricity, and Energy Conservation Technology - Republic of Indonesia E-mail address: al_irsyad21@yahoo.com
} 
requires a goal consensus among stakeholders, although this rarely happens for government projections (Ascher, 1978). In light of this, political willingness highly influences the commitment to implement renewable energy targets (Yi and Feiock, 2014). One of the most committed countries is China, which is becoming the leader on renewables (REN21, 2017). However, China cannot maximise its operation of plants for renewables due to the interconnection problems and low-efficiency technologies (Wang et al., 2010). Hence, the government commitment does not necessarily guarantee the achievement of projections of renewable energy productions. One of the identified inaccuracy sources is wrong assumptions in the applicable projection models (Linderoth, 2002; O'Neill and Desai, 2005). Making the appropriate assumptions for a projection needs a comprehensive knowledge of the analyzed system (Ascher, 1978).

We aim to improve understanding of the error patterns in renewable energy-based electricity projections. O'Neill and Desai (2005) and Winebrake and Sakva (2006) suggest that incorrect macroeconomic assumptions are sources of fossil energy projection errors, while we view government commitments and technical issues as the main grounds for renewable projections deviation. The commitments are influenced by economic, environmental and political factors which vary in each country (Marques et al., 2011). The commitments, along with other institutional issues, determine the achievement of renewable capacity targets while technical issues impact on electricity production targets. One of important technical issues is the assumption for capacity factor which is a ratio of actual electricity production in a year to its potential production based on the rated power capacity. The capacity factor of renewable power plant varies depending on technology and location (Capellaro, 2016; He and Kammen, 2016).

Several studies have already analyzed the accuracy of renewable-related projections, but the scope of their analysis is relatively limited for drawing broad conclusions. Gilbert and Sovacool (2016) focused on projections in the US Annual Energy Outlook (AEO), thus their results could not capture global trends. Similarly, Metayer et al. (2015) analyzed global level projections in the World Energy Outlook (WEO) and, as a consequence, ignored the cancellation effect of the failures and the successes of projection implementation in each country. We extend the scope in our analysis to the United States (US) and the European Union (EU) countries, which have a strong motivation to have green electricity supply installed. The US is the second largest country in renewable capacity while the EU countries are the leaders for non-hydro renewable capacity per capita (REN21, 2017). The US and EU countries also provide projections of annual renewable energy capacity and production, thus allowing us to analyze the errors in different time horizons. Errors in capacity projection indicate the effectiveness of the renewable energy policy used to pull the investment while errors in production projection reflect the validity of assumptions used in the energy models. We also examine the dominant error sources by comparing errors in the projections of capacity and production of renewable energy and this is another advance from previous studies.

Our research questions are as follows: What is the most achievable renewable energy target? What is the projection error range for different renewable types? And which error is dominant? Our analysis uses three indicators, i.e. mean percentage error (MPE), mean absolute percentage error (MAPE), and the mean of the difference of absolute percentage error of capacity and absolute percentage error of generation (MDAPE). These terms are defined in Section 3.2 on methodology. The contribution of this study is threefold. First, our study guides policy makers to understand the uncertainty and errors of their renewable targets. Second, the results, by providing information about the most achievable renewable targets, may assist risk-averse countries to secure their energy supply. Last, we identify the issues that need more attention in renewable energy planning. 
The remainder of the paper is organized as follows: Section 2 discusses previous studies on energy projection accuracy; the data and methodology are described in Section 3; while Section 4 presents the results of our analysis; and Section 5 discusses the implications of the findings for renewable energy policy and concludes the analysis.

\section{Literature Review}

Energy models are the main tools for energy projections. The US Energy Information Administration (EIA) used the Intermediate Future Forecasting System (IFFS) model from 1982 to1993 and has applied the National Energy Modelling System (NEMS) since 1994 for creating projections in the AEO. EU countries have used various energy models to develop the National Renewable Energy Action Plan (NREAP). For instance, Greece used the Integrated Energy and Power Evaluation Program (ENPEP), MARKAL-EFOM System (TIMES), and Wien Automatic System Planning Package (WASP) (MEECC, 2010; Winebrake and Sakva, 2006). However, many studies criticise the use of energy models for projection purposes due to energy model limitations (Jefferson, 2014; Li et al., 2015a; Schwanitz, 2013). The energy models cannot perfectly represent the complexity of future energy systems and commonly use incorrect assumptions for the unknown parameters (Pindyck, 2015; Schwanitz, 2013; Trutnevyte et al., 2016; Weijermars et al., 2012).

Energy projections with large errors will result in inefficient resource usage, excessive emissions and weaker energy security (Metayer et al., 2015). Therefore, analysing the accuracy of energy models is important to derive insights related to uncertainty and inaccuracy sources (O'Neill and Desai, 2005; Sanders et al., 2009; Winebrake and Sakva, 2006). Sohn (2007) evaluated global energy consumption projections by types and found environmental policy as a cause of the large errors in coal projections. Sanders et al. (2009) analysed the energy price forecasts by the US Department of Energy (DOE) and then used their findings as a basis for suggested forecast adjustments. Winebrake and Sakva (2006) assessed sectoral energy consumption projection errors in the AEO and concluded that projections in several sectors had systemic modeling problems, which require significant corrections.

Metayer et al. (2015) analyzed the projections for various renewables, as well as fossil energy, in the WEO published by the International Energy Agency (IEA) between 1994 and 2014. Their analysis results found that the IEA intentionally underestimated the renewable projections to justify the high growth of fossil energy projections. They questioned the WEO's decision to continue using linear growth assumption for renewables where in fact historical data already showed exponential growth. The consequences were inefficient economic costs and emissions from excessive conventional energy investments. The underestimated projections were for solar photovoltaic (PV) and wind energy, while other renewables had an overestimated or relatively accurate projection. Nevertheless, global analysis results by Metayer et al. (2015) cannot be generalized since not all countries can exceed their renewable targets.

Gilbert and Sovacool (2016) investigated the inaccuracy of six projections for renewables in the US AEO published by the EIA from 2004 to 2014. Similarly, Gilbert and Sovacool (2016) focussed on analysing modelling bias and found consistent underestimated projections for wind and solar energies. They also recognized that the EIA initially overestimated capacity factors for solar and wind energies, though the EIA has fixed it in recent projections. They concluded that the underestimated projections were the result of systemic errors in NEMS structure, policy improvements, and falling technology prices. Carley (2009) and Shrimali et al. (2015) supported their conclusions by empirically showing the effectiveness of renewable energy policy in the US. However, Carley (2009) found that the policy may 
effectively increase the total investment and capacity but not the renewable share in electricity supply mix.

As a synthesis of the literature, political will and technical issues influence the implementation level of targets for renewable capacity and production respectively. Transition in an energy system is not automatic and requires government intervention. Therefore, energy projections should be equipped with achievement strategies, describing the necessary policies (Bhattacharyya and Timilsina, 2010; Weijermars et al., 2012). The government must communicate the policies to stakeholders and maintain the credibility of the policies (Szabó et al., 2014; Taylor et al., 2014). An inappropriate policy may result in delays or even cancellation of the viable investments (Tang, 2013). On the other hand, the intermittency and unreliable technology can potentially overestimate the capacity factor of renewable energy. Such technical issues become the main barriers to implementing a $100 \%$ renewable energy supply proposal (Delucchi and Jacobson, 2011; Heard et al., 2017; Jacobson and Delucchi, 2011; Lucas, 2017).

\section{Data and Methodology}

\subsection{Data}

Accuracy analysis for renewable energy projections in multiple, committed countries will improve the robustness of the analysis results. The size of renewable energy capacity reflects the country's commitment and the top six countries with the largest renewables capacity in 2016 were China, the US, Germany, Japan, India, and Italy consecutively (REN21, 2017). However, we have excluded China, Japan, and India from the analysis because we cannot obtain their projections of renewables-based electricity production. ANRE (2014), METI (2015), MNRE (2011, 2017), and Moch (2014) only present their capacity projections. EU countries have stated targets of renewables capacity and production in NREAP. The targets and detailed policies for each country are available at the European Commission website (EC, 2016b). We have retrieved actual data from 2010 to 2014 from the EU Commission website (EC, 2016a). The US EIA annually publishes various energy-related projections in the AEO and the actual data (EIA, 2016a, b). Our analysis uses the reference case scenarios from AEO 2005 to 2014.

Most of the capacity and generation projections are available for all renewable energy types, except biomass, waste to energy power, and solar thermal. We cannot obtain actual capacity data for biomass and waste to energy, and actual generation data for solar thermal in the EU countries. Meanwhile, actual data for US solar thermal is also mixed with actual data for the photovoltaic. As a consequence, we integrate the analysis of the projection errors for solar thermal to PV analysis, and we also do not analyze the projection errors of biomass capacity. The total renewable energy capacity target ${ }^{2}$ for the US and EU in 2014 was $481.79 \mathrm{GW}$, consisting of hydropower (47.8\%), wind energy (40.4\%), solar energy (10.9\%), geothermal (0.9\%) and ocean energy (0.1\%).

\subsection{Methodology}

We use the approach in Winebrake and Sakva (2006) to evaluate the projection errors. Winebrake and Sakva (2006) use mean percentage error (MPE) which could show error patterns in short and long

\footnotetext{
${ }^{2}$ Based on AEO 2010 and NREAP.
} 
terms. MPE is defined as average error between $\hat{Y}$ forecast data and $Y$ actual data for $n$ number of projections in $\tau$ year forecast horizon and $j$ energy type as in Equation (1):

$M P E_{\tau, j}=\frac{\sum_{t} \frac{{ }^{\left(\widehat{Y}_{t, \tau, j}-Y_{t, \tau, j}\right)}}{Y_{t, \tau, j}}}{n_{\tau, j}}$

where $t$ is projection publication year. MPE shows the error direction, i.e. whether the projection is overestimated (MPE $>0$ ) or underestimated (MPE $<0)$.

We also analyze the mean absolute percentage error (MAPE) as in Equation (2) to compensate for the cancellation effect between overestimated and underestimated electricity production projections.

$M A P E_{\tau, j}=\frac{\left|\sum_{t} \frac{\left(\widehat{Y}_{t, \tau, j}-Y_{t, \tau, j}\right)}{Y_{t, \tau, j}}\right|}{n_{\tau, j}}$

Here, to understand the dominant errors of capacity and generation projections of renewable energy, we introduce a new indicator, named the mean of the difference of absolute percentage error of capacity and absolute percentage error of generation (MDAPE), as in Equation (3), which examines the dominance of the errors, i.e., capacity projection error and production projection error.

$\operatorname{MDAPE} E_{\tau, j}=\frac{\sum\left(\left|\frac{\hat{Y}_{t, \tau, j}-Y_{t, \tau, j}}{Y_{t, \tau, j}}\right|_{\text {Capacity }}-\left|\frac{Y_{t, \tau, j}-Y_{t, \tau, j}}{Y_{t, \tau, j}}\right|_{\text {Generation }}\right)}{n_{\tau, j}}$

We interpret MDAPE as an indicator to represent the dominant error source. Positive MDAPE means that the projection has more problems considering political and policy issues while negative MDAPE means more technical issues. However, we should reiterate that the problems could be either underestimated or overestimated projections.

Some errors are very large for several reasons, such as zero implementation and unplanned production. In order to enhance the analysis, we limit the error value to a minimum of minus 100 for the highly underestimated projections, which have an error of minus 100 or smaller, to a maximum of plus 100 for the highly overestimated projections which have error of plus 100 or higher.

\section{Results}

The equations above (1,2 and 3) have been applied to the energy projections data for the US and EU countries derived from (EC, 2016a, b; EIA, 2016a, b) and the results for the different renewable energy sources are shown in Tables 1 to 6.

\subsection{Wind Energy Projection Errors}

Positive figures for average MPEs in Table 1 show that the over projection of wind capacity and generation is common. Several countries, such as Malta, have not been able to implement wind turbine capacity targets at all, while Slovenia was three years behind schedule in constructing 4 MW wind turbines. However, longer projections do not necessarily have larger projection errors. Large errors in the one-year projection of wind capacity indicate the presence of barriers and gradual policy implementations in the early stage of wind energy deployment. Construction delays may come from outside of policy issues, such as rejections by small groups of local people in the UK (Bell et al., 2013). 
Furthermore, negative signs of average MDAPE in Table 1 mean that most countries have more problems on the technical issues of wind energy. Cyprus, Denmark, Latvia, Luxembourg, Poland and Sweden are unable to reach production targets, although they can meet their capacity targets. Slovenia does not generate any electricity from wind power in spite of implementing $4 \mathrm{MW}$ of $8 \mathrm{MW}$ wind capacity target since 2013 .

\subsection{Solar Power Projection Errors}

Solar energy targets are more achievable compared to wind power. Solar energy may have the highest costs, but its investment has low risks due to easy resource assessment, low social impact, short construction period, and a shorter payback period (Li et al., 2015b). Moreover, solar energy policy has been accepted so that most countries can exceed their capacity targets. The average MPEs of capacity and generation are negative, and become larger in longer projection horizons as shown in Table 2 . The average MDAPEs are positive, indicating the dominance of capacity projection errors. Lithuania, Poland, and Romania had larger actual capacity than their targets while Finland and Ireland did not have solar energy targets at first, but finally produced PV based electricity. Similar achievement by the US caused the EIA to revise the AEO in the following years, but the actual growth was always higher than the revised projections. The US policies and declining technology price have successfully attracted solar energy investments and thus solar energy supply exhibits an exponential growth trend since 2012 (Carley, 2009; Gilbert and Sovacool, 2016; Shrimali et al., 2015). Since most average MPEs of capacity and generation are negative, the positive average MDAPEs should be interpreted as the overestimation of the capacity factor. For example, in the one-year projections, the production target cannot be reached even though the actual capacity was, on average, $11.8 \%$ higher than the capacity projections.

A small part of solar energy projections is solar thermal, which cannot be implemented by most countries. Cyprus, France, Italy, and Portugal could not attain their targets at all while Spain met its targets partially. Other countries did not have solar thermal targets, indicating higher risks on this energy investment. An exception is Germany which had no target, but has reported a 2 MW capacity of solar thermal since 2010 .

\subsection{Hydro Power Projection Errors}

Hydro power is another commonly proposed renewable energy source, along with wind and solar energy. The larger error of hydro capacity projection in Table 3 does not always trigger a larger error of electricity production projection, as in Bulgaria. Interestingly, some countries, such as Estonia, Luxemburg, Portugal and United Kingdom, failed to fulfill capacity projections but could exceed the production projection. We suspect the assumption of capacity factor for hydro power plant has been underestimated.

Most of the errors in Table 3 are relatively stable over the years of projection and the average MPEs and MDAPE are relatively low and steady. All these indicators suggest that the hydro power projections were made more carefully, for example by only counting the feasible hydro power potential. The increasing average MPEs of the technology capacity indicates that hydro capacity target becomes more unachievable in the long-term. Similarly, the diminishing average MPEs of the generation shows that the surplus of the production target becomes smaller in the longer projection horizon. For example in the US, AEO forecast stable hydro electricity production but in reality, the production was 
continuously declining. We should note that incorrect reference data causes significant projection errors in several countries. For example, initial data in 2005 for projections in Spain and UK are different to the actual data, thus the projection will not converge to the actual data.

\subsection{Marine Energy Projection Errors}

Only France and Portugal had marine energy targets for 2010 to 2014, while the UK had a target in 2016 as shown in Table 4. Table 4 also shows that Portugal failed to reach its 5 MW marine energy target in 2010 and had to wait until 2014 to have 1 MW of installed capacity. France could reach the capacity target as indicated by low MPEs of capacity, while the UK could accelerate the electricity production target for 2010. The average MPEs of the generation targets becomes larger in the longer horizon even though the average MPEs of the capacity targets are relatively small. France, for instance, had an MPE of generation in five-year forecast horizon of 27.9\%, while the MPE of capacity was only $7.8 \%$. Correspondingly, the average MDAPE also suggests that countries with marine energy projections should revise their assumptions of capacity factors and other technical issues. We suggest that future projections should more carefully consider the various marine energy challenges as pointed out by Dalton (2009), MacGillivray et al. (2013), and Magagna and Uihlein (2015). Some of the challenges delaying the construction are the lengthy permit process and the financing institutions lacking knowledge of marine energy risks (Dalton, 2009).

\subsection{Geothermal Projection Errors}

Most EU countries did not set geothermal targets and those setting targets in 2010 to 2015 failed to realize the targets, as shown in Table 5. Czech Republic and Hungary could not meet any targeted geothermal capacity while France built a small portion of the capacity target in 2011, but cannot generate electricity. Czech Republic and Hungary have smaller MPEs than France because they set the capacity targets for 2013, so have no projection errors in 2010-2012. As an exception, Germany and Italy successfully added new capacity yet it is still smaller than the projections. Only Portugal exceeded its electricity supply projection based on its initial capacity, but over time the supply surplus becomes smaller due to no implementation of the new capacity target. The US expected high growth of geothermal sources in AEO 2006 - 2010 but finally realized that the expectations were unrealistic; and then reduced the growth target in AEO 2011 - 2014. All these overestimated projections are indicated by positive errors in Table 5 . Surprisingly, the average MDAPEs have negative values, meaning that the production is more unpredictable than the capacity projections. The geothermal power plants in Austria and Slovakia failed to generate electricity and the capacity factor of geothermal power plants in Germany were not as high as expected.

\subsection{Biomass and Waste to Energy Projection Errors}

A high target for biomass and waste to energy sources is common. As we mentioned before in the data section that we cannot obtain the capacity data, our analysis results in Table 6 only shows errors in generation projection. Most countries could exceed their projections but some still had difficulty to implement the targets. Average MAPEs of the projection errors are over $20 \%$ for all projection horizons. For example, Malta had a target to produce electricity from biomass and waste energy of $139.8 \mathrm{GWh}$, 
or $73 \%$ of total renewables-based electricity projection in 2014 , but the actual production was only 7 GWh. Most targets were achievable in the short-run but not in the long-run. Therefore, future projections should more carefully assume the continuity of biomass and waste to energy resource. Optimal biomass resources require supply management for the planting and harvesting process that may take several months (Park et al., 2013; Uri et al., 2015).

\section{Implications of Assessing Errors in Renewable Energy Projections}

Renewable energy has specific challenges such as higher investment costs, less reliable technology, and intermittent supply issues. Consequently, projecting renewable energy capacity demands a high level of government commitment to provide incentives, to accept higher electricity costs, to settle the contradicting policies, and to have a less reliable energy system. The commitment often changes in response to national economic conditions, global energy prices, and political pressures. Another important factor affecting the commitment is the actual performance of renewables in producing electricity. Renewables-based electricity production is highly concerned with technical issues, e.g., technology reliability, efficiency, resource intermittency, and capacity factors.

Solar energy projections are more achievable compared to the other analysed renewables. However it should be noted that the analysed solar energy targets are smaller than wind and hydropower targets. We also found that most solar energy projections had been underestimated especially the capacity projections. Characteristics of easy installation, more available potential data, and a wide-range of capacity sizes available in the market, cause solar energy to be a low-risk investment. Other factors include demand-adjustable technology, definitive construction period, low-cost resource assessment, and being socially acceptable. Therefore, policy makers could expect high solar capacity additions from an attractive incentive policy. Simple economic feasibility is already adequate to determine solar energy investment (Robinson and Rai, 2015).

In contrast, many EU countries were struggling to implement wind energy targets, especially in electricity generation. This finding indicates wind turbines have higher technical problems compared to solar energy. Exceeding the wind capacity target does not guarantee the achievement of production targets (e.g. Cyprus in Table 1). This emphasizes the importances of reliable wind pattern forecasts and advanced technology for low-speed generators in setting capacity factor assumptions. Similarly, marine energy still faces high investment failure risk and most countries have now realized it. Therefore, we predict the marine energy growth will remain low until more reliable and feasible technology is made available. Other countries should learn from the US and the UK experiences for wind and marine energy development respectively.

Dispatchable renewables have different projection error patterns. Hydro power capacity targets cannot be reached on average, but its production targets are more attainable. Several countries who were successfully implementing hydro power capacity and productions targets are Belgium, Bulgaria, Czech, Ireland, Italy, and Poland. Most of the projections have underestimated the capacity factors of existing hydro power plants, while new capacity targets on average are not implementable. The average errors of hydro power projections within five-year projection horizon are the smallest but the trend becomes unattainable. These findings suggest that hydro power projections should deal with long-term technical issues, such as declining power plant efficiency and water conservation. 
Table 1 Errors of wind power projections

\begin{tabular}{|c|c|c|c|c|c|c|c|c|c|c|c|c|c|c|c|}
\hline \multirow{2}{*}{$\begin{array}{l}\text { Forecast } \\
\text { horizon (years) }\end{array}$} & \multicolumn{5}{|c|}{ MPE of Capacity (\%) } & \multicolumn{5}{|c|}{ MPE of Generation (\%) } & \multicolumn{5}{|c|}{ MDAPE (\%) } \\
\hline & 1 & 2 & 3 & 4 & 5 & 1 & 2 & 3 & 4 & 5 & 1 & 2 & 3 & 4 & 5 \\
\hline Austria & 3.1 & 8.6 & 8.7 & 6.2 & 2.1 & -1.5 & 12.8 & 13.7 & 10.6 & 6.7 & 1.6 & -5.7 & -6.0 & -4.4 & -2.5 \\
\hline Belgium & -19.6 & -12.3 & -11.8 & -13.9 & -13.1 & -23.3 & -23.9 & -14.6 & -7.6 & -3.2 & -3.7 & -11.6 & -5.6 & -2.4 & -2.8 \\
\hline Bulgaria & -31.1 & -13.8 & -4.5 & 7.5 & 17.8 & -11.2 & 3.0 & 6.6 & 12.0 & 19.8 & 20.0 & 3.2 & 2.2 & 5.4 & 6.0 \\
\hline Cyprus & 0.0 & -7.5 & -12.5 & -6.3 & -2.6 & 1.3 & 33.5 & 23.1 & 22.1 & 27.9 & -1.3 & -26.1 & -10.6 & -9.7 & -15.5 \\
\hline Czech Republic & 14.1 & 25.8 & 28.2 & 33.6 & 38.8 & 35.5 & 38.0 & 45.2 & 48.7 & 55.5 & -21.4 & -12.2 & -17.0 & -15.1 & -16.7 \\
\hline Denmark & -5.7 & -5.1 & -6.0 & -7.6 & -8.8 & 10.2 & 2.9 & 0.0 & 0.5 & -2.3 & -4.5 & -2.3 & -0.8 & 2.0 & 1.7 \\
\hline Estonia & 36.1 & 17.5 & 17.3 & 23.3 & 22.1 & 21.7 & 9.1 & 5.9 & 15.2 & 20.5 & 14.5 & 6.0 & 9.5 & 6.6 & 0.5 \\
\hline Finland & -13.7 & 13.5 & 25.0 & 20.6 & 14.9 & 22.4 & 22.6 & 37.0 & 37.0 & 32.9 & -8.7 & 4.6 & -2.9 & -9.6 & -9.5 \\
\hline France & -6.3 & -2.0 & 2.0 & 6.5 & 10.7 & 17.0 & 18.0 & 18.8 & 23.2 & 28.8 & -10.8 & -13.8 & -12.7 & -13.6 & -15.6 \\
\hline Germany & 1.8 & 1.9 & 1.3 & -0.2 & -2.4 & 18.2 & 9.6 & 8.0 & 8.7 & 9.2 & -16.4 & -7.8 & -6.7 & -6.5 & -5.2 \\
\hline Greece & 2.2 & 9.8 & 21.1 & 33.9 & 44.7 & 15.3 & 25.5 & 34.2 & 43.7 & 60.6 & -13.1 & -15.8 & -13.1 & -9.7 & -15.9 \\
\hline Hungary & 12.6 & 15.7 & 22.8 & 34.0 & 41.7 & 29.6 & 20.1 & 20.3 & 30.2 & 43.9 & -17.0 & -4.4 & 2.5 & 3.8 & -2.1 \\
\hline Ireland & 52.0 & 47.3 & 43.0 & 43.2 & 40.9 & 71.1 & 53.6 & 53.9 & 56.6 & 55.4 & -19.2 & -6.4 & -10.9 & -13.4 & -14.6 \\
\hline Italy & 0.1 & -3.5 & -6.7 & -7.3 & -6.5 & -8.0 & -6.5 & -12.0 & -14.7 & -15.2 & -7.9 & -2.9 & -5.2 & -7.3 & -8.6 \\
\hline Latvia & -6.7 & -1.9 & -6.9 & -6.7 & -2.2 & 18.4 & 10.6 & 3.0 & 5.1 & 8.9 & -11.7 & -5.9 & -2.4 & -3.2 & -4.2 \\
\hline Lithuania & 34.6 & 16.8 & 8.2 & 8.0 & 10.7 & 32.6 & 16.1 & 12.1 & 12.6 & 15.6 & 2.0 & 1.3 & 2.5 & 0.2 & -1.0 \\
\hline Luxembourg & -20.5 & -15.8 & -12.8 & -4.0 & 7.5 & 9.1 & 10.0 & 15.8 & 26.0 & 41.5 & 11.4 & 5.8 & -2.9 & -10.8 & -18.7 \\
\hline Malta & 100.0 & 100.0 & 100.0 & 100.0 & 100.0 & 100.0 & 100.0 & 100.0 & 100.0 & 100.0 & 0 & 0 & 0 & 0 & 0 \\
\hline Netherlands & -0.7 & -2.4 & 5.6 & 12.4 & 24.0 & 11.9 & -0.2 & 10.5 & 19.9 & 36.6 & -11.2 & -9.8 & -10.0 & -11.3 & -15.6 \\
\hline Poland & -0.7 & -7.3 & -12.2 & -16.3 & -17.9 & 38.8 & 20.2 & 10.3 & 4.7 & 0.4 & -38.1 & -12.9 & -4.4 & 0.8 & 2.1 \\
\hline Portugal & 12.1 & 14.0 & 18.3 & 19.1 & 18.3 & 11.2 & 17.5 & 19.3 & 15.7 & 13.3 & 0.9 & -3.5 & -1.0 & 3.4 & 5.0 \\
\hline Romania & 44.0 & 35.2 & 24.0 & 15.1 & 9.8 & 50.3 & 47.1 & 39.9 & 30.6 & 23.7 & -6.4 & -11.9 & -15.9 & -9.7 & -6.3 \\
\hline Slovakia & 66.7 & 66.7 & 77.8 & 83.3 & 86.7 & 16.7 & 38.3 & 58.9 & 69.2 & 75.3 & 50.0 & 28.3 & 18.9 & 14.2 & 11.3 \\
\hline Slovenia & 100.0 & 100.0 & 100.0 & 100.0 & 100.0 & 100.0 & 100.0 & 100.0 & 100.0 & 100.0 & 0.0 & 0.0 & 0.0 & 0.0 & 0.0 \\
\hline Spain & -2.6 & -0.5 & 0.8 & 2.8 & 5.3 & -7.4 & -2.8 & -3.4 & -4.7 & -3.0 & -4.8 & -2.5 & -2.0 & -1.5 & 1.1 \\
\hline Sweden & -7.2 & -15.0 & -21.1 & -24.8 & -28.3 & 36.9 & 14.2 & 5.6 & -2.8 & -8.2 & -29.6 & -7.7 & 2.1 & 3.7 & 5.4 \\
\hline United Kingdom & 0.5 & 6.3 & 3.2 & 0.1 & -1.5 & 38.0 & 30.1 & 25.7 & 18.7 & 15.7 & -37.4 & -23.8 & -20.4 & -13.6 & -10.1 \\
\hline United States & -6.5 & -14.7 & -23.8 & -31.7 & -40.0 & 8.2 & 0.9 & -9.4 & -18.9 & -31.0 & -9.1 & 0.2 & 4.3 & 0.6 & 2.7 \\
\hline Minimum & -31.1 & -15.8 & -23.8 & -31.7 & -40.0 & -23.3 & -23.9 & -14.6 & -18.9 & -31.0 & -38.1 & -26.1 & -20.4 & -15.1 & -18.7 \\
\hline Average & 12.8 & 13.5 & 13.9 & 15.4 & 16.9 & 22.9 & 21.7 & 22.3 & 24.3 & 26.9 & -6.1 & -4.9 & -3.9 & -3.6 & -4.6 \\
\hline Maximum & 100.0 & 100.0 & 100.0 & 100.0 & 100.0 & 100.0 & 100.0 & 100.0 & 100.0 & 100.0 & 50.0 & 28.3 & 18.9 & 14.2 & 11.3 \\
\hline
\end{tabular}


Table 2 Errors of solar power projections

\begin{tabular}{|c|c|c|c|c|c|c|c|c|c|c|c|c|c|c|c|}
\hline \multirow{2}{*}{$\begin{array}{l}\text { Forecast } \\
\text { horizon (years) }\end{array}$} & \multicolumn{5}{|c|}{ MPE of Capacity (\%) } & \multicolumn{5}{|c|}{ MPE of Generation (\%) } & \multicolumn{5}{|c|}{ MDAPE (\%) } \\
\hline & 1 & 2 & 3 & 4 & 5 & 1 & 2 & 3 & 4 & 5 & 1 & 2 & 3 & 4 & 5 \\
\hline Austria & -41.6 & -54.4 & -58.6 & -63.4 & -66.7 & -4.5 & -23.8 & -37.9 & -47.8 & -54.5 & 37.1 & 30.6 & 20.6 & 15.6 & 12.3 \\
\hline Belgium & -61.3 & -65.3 & -70.6 & -73.3 & -74.5 & -45.7 & -57.0 & -64.9 & -69.2 & -71.7 & 15.6 & 8.2 & 5.7 & 4.0 & 2.8 \\
\hline Bulgaria & -64.0 & -69.7 & -77.3 & -79.8 & -80.2 & -20.0 & -35.2 & -53.1 & -61.6 & -65.4 & 44.0 & 34.4 & 24.2 & 18.2 & 14.8 \\
\hline Cyprus & -14.3 & -17.1 & -21.2 & -28.8 & -17.1 & -7.7 & 0.3 & -4.3 & -13.9 & 8.9 & 6.6 & 9.1 & 11.3 & 10.7 & -5.5 \\
\hline Czech Republic & -4.5 & -8.8 & -11.8 & -13.6 & -14.7 & -6.2 & -14.5 & -16.7 & -16.7 & -17.3 & -1.7 & -5.6 & -4.9 & -3.1 & -2.6 \\
\hline Denmark & -57.1 & -69.7 & -79.6 & -84.6 & -87.5 & -66.7 & -76.7 & -83.8 & -87.8 & -90.1 & -9.5 & -6.9 & -4.2 & -3.2 & -2.6 \\
\hline \multicolumn{16}{|l|}{ Estonia } \\
\hline Finland & -100.0 & -100.0 & -100.0 & -100.0 & -100.0 & -100.0 & -100.0 & -100.0 & -100.0 & -100.0 & 0.0 & 0.0 & 0.0 & 0.0 & 0.0 \\
\hline France & -51.7 & -61.9 & -65.4 & -66.1 & -66.2 & -1.1 & -27.8 & -40.6 & -45.8 & -48.6 & 50.6 & 34.2 & 24.7 & 20.3 & 17.6 \\
\hline Germany & 10.1 & 14.5 & 18.7 & 20.3 & 20.1 & -19.0 & -23.9 & -27.3 & -29.1 & -30.4 & -8.9 & -9.3 & -8.5 & -8.8 & -10.3 \\
\hline Greece & -8.9 & -25.3 & -38.7 & -46.5 & -49.3 & 53.2 & 15.1 & -9.5 & -25.1 & -33.0 & -44.3 & -12.8 & -6.3 & -5.3 & -5.0 \\
\hline Hungary & -100.0 & -75.0 & -66.7 & -68.6 & -71.2 & 100.0 & 100.0 & 70.8 & 42.1 & 20.8 & 0.0 & -25.0 & -4.2 & 4.4 & 7.1 \\
\hline Ireland & -100.0 & -100.0 & -100.0 & -100.0 & -100.0 & 0.0 & -50.0 & -66.7 & -75.0 & -80.0 & 100.0 & 50.0 & 33.3 & 25.0 & 20.0 \\
\hline Italy & -27.8 & -50.2 & -58.6 & -62.8 & -64.8 & 3.7 & -32.8 & -48.0 & -55.5 & -59.4 & 24.1 & 13.7 & 8.2 & 5.5 & 3.9 \\
\hline Latvia & 0.0 & 0.0 & 33.3 & 50.0 & 60.0 & 0.0 & 0.0 & 33.3 & 50.0 & 60.0 & 0.0 & 0.0 & 0.0 & 0.0 & 0.0 \\
\hline Lithuania & 100.0 & 100.0 & 47.6 & 12.6 & -7.6 & 0.0 & 50.0 & 50.0 & 15.8 & -4.9 & 100.0 & 50.0 & 35.7 & 28.3 & 22.8 \\
\hline Luxembourg & -6.9 & -20.5 & -29.7 & -35.4 & -36.3 & -4.8 & -13.9 & -17.2 & -26.4 & -30.8 & 2.1 & 6.6 & 12.5 & 9.0 & 5.5 \\
\hline Malta & 100.0 & 45.9 & 19.5 & 13.2 & 0.2 & 100.0 & 70.2 & 45.5 & 43.9 & 27.1 & 0.0 & -16.1 & -0.9 & -9.1 & -5.0 \\
\hline Netherlands & 2.2 & 1.1 & -15.9 & -29.2 & -38.2 & 30.4 & 15.2 & -3.7 & -19.2 & -30.3 & -28.1 & -14.1 & -6.6 & -4.1 & -3.3 \\
\hline Poland & 100.0 & 50.0 & 66.7 & 50.0 & 21.5 & 100.0 & 100.0 & 100.0 & 100.0 & 65.7 & 0.0 & -50.0 & -33.3 & -50.0 & -35.8 \\
\hline Portugal & 16.4 & 33.2 & 36.4 & 41.6 & 41.7 & 9.0 & 25.2 & 27.8 & 33.9 & 37.1 & 7.4 & 8.0 & 8.6 & 7.7 & 4.7 \\
\hline Romania & 0.0 & 50.0 & 35.0 & 3.8 & -15.2 & 0.0 & 50.0 & 66.7 & 31.0 & 6.5 & 0.0 & 0.0 & -31.7 & -20.4 & -16.3 \\
\hline Slovakia & 100.0 & 70.0 & 21.8 & -2.1 & -16.1 & 76.5 & -0.4 & -23.4 & -36.6 & -44.3 & 100.0 & 68.9 & 47.7 & 35.2 & 27.5 \\
\hline Slovenia & 0.0 & -35.1 & -51.6 & -60.1 & -65.2 & -7.7 & -40.8 & -56.0 & -63.9 & -68.6 & -7.7 & -5.7 & -4.5 & -3.8 & -3.4 \\
\hline Spain & 0.0 & 3.4 & 3.8 & 5.0 & 7.4 & 5.2 & 5.5 & 5.3 & 6.8 & 9.0 & -5.2 & -2.1 & -1.5 & -1.8 & -1.6 \\
\hline Sweden & -51.8 & -52.6 & -60.2 & -66.6 & -71.1 & -84.4 & -84.5 & -86.3 & -88.2 & -89.5 & -32.6 & -31.9 & -26.1 & -21.6 & -18.4 \\
\hline United Kingdom & -47.9 & -66.9 & -72.6 & -75.2 & -77.4 & -2.4 & -26.6 & -45.2 & -53.7 & -60.0 & 45.5 & 40.3 & 27.5 & 21.5 & 17.5 \\
\hline United States & -10.3 & -22.8 & -38.2 & -49.5 & -59.4 & 12.2 & 3.6 & -13.9 & -31.1 & -41.9 & -11.5 & -12.8 & -4.5 & 9.0 & 10.8 \\
\hline Minimum & -100.0 & -100.0 & -100.0 & -100.0 & -100.0 & -100.0 & -100.0 & -100.0 & -100.0 & -100.0 & -44.3 & -50.0 & -33.3 & -50.0 & -35.8 \\
\hline Average & -11.8 & -19.5 & -27.2 & -33.7 & -38.1 & 4.4 & -6.4 & -14.8 & -23.1 & -29.1 & 14.7 & 6.0 & 4.5 & 3.1 & 2.1 \\
\hline Maximum & 100.0 & 100.0 & 66.7 & 50.0 & 60.0 & 100.0 & 100.0 & 100.0 & 100.0 & 65.7 & 100.0 & 68.9 & 47.7 & 35.2 & 27.5 \\
\hline
\end{tabular}

Source: Analysis by authors based on data (EC, 2016a, b; EIA, 2016a, b) 
Table 3 Errors of hydro power projections

\begin{tabular}{|c|c|c|c|c|c|c|c|c|c|c|c|c|c|c|c|}
\hline \multirow{2}{*}{$\begin{array}{l}\text { Forecast } \\
\text { horizon (years) }\end{array}$} & \multicolumn{5}{|c|}{ MPE of Capacity (\%) } & \multicolumn{5}{|c|}{ MPE of Generation (\%) } & \multicolumn{5}{|c|}{ MDAPE (\%) } \\
\hline & 1 & 2 & 3 & 4 & 5 & 1 & 2 & 3 & 4 & 5 & 1 & 2 & 3 & 4 & 5 \\
\hline Austria & -1.5 & -2.4 & -2.9 & -3.2 & -3.5 & -0.7 & 4.4 & -1.4 & -3.3 & -3.9 & 0.8 & -2.7 & -4.8 & -4.8 & -4.2 \\
\hline Belgium & -92.1 & -92.1 & -92.1 & -92.1 & -92.0 & -78.3 & -76.2 & -76.6 & -77.0 & -76.5 & 13.8 & 15.9 & 15.4 & 15.1 & 15.5 \\
\hline Bulgaria & -2.3 & -2.0 & -2.5 & -2.9 & -3.1 & -43.4 & -26.7 & -23.1 & -24.7 & -26.6 & -41.1 & -24.7 & -20.5 & -21.8 & -23.5 \\
\hline \multicolumn{16}{|l|}{ Cyprus } \\
\hline Czech Republic & -52.3 & -52.1 & -52.0 & -52.0 & -52.0 & -37.6 & -28.8 & -27.5 & -30.6 & -29.6 & 14.7 & 23.3 & 24.5 & 21.5 & 22.5 \\
\hline Denmark & 11.1 & 11.1 & 11.1 & 11.1 & 13.9 & 47.6 & 65.0 & 70.8 & 78.1 & 82.5 & -36.5 & -53.9 & -59.7 & -67.0 & -68.6 \\
\hline Estonia & 20.0 & 38.0 & 24.5 & 17.8 & 25.4 & -3.7 & -1.9 & -10.8 & -4.2 & -1.2 & 16.3 & 36.1 & 15.4 & 8.3 & 15.6 \\
\hline Finland & -3.0 & -3.6 & -3.8 & -4.2 & -4.5 & 10.0 & 12.2 & 2.9 & 4.9 & 5.1 & -7.0 & -8.5 & -9.5 & -8.5 & -6.9 \\
\hline France & 3.2 & 4.1 & 5.0 & 5.8 & 6.6 & 9.8 & 29.7 & 25.9 & 19.3 & 17.6 & -6.6 & -25.6 & -20.9 & -13.7 & -11.1 \\
\hline Germany & -6.0 & -6.8 & -6.5 & -6.3 & -6.1 & -8.6 & -1.2 & -4.2 & -5.6 & -4.0 & -2.7 & -0.7 & -1.9 & -2.4 & -1.3 \\
\hline Greece & 22.5 & 22.4 & 24.2 & 26.3 & 26.5 & -23.0 & 6.8 & 15.7 & 11.8 & 17.3 & -0.5 & -7.4 & -6.9 & 3.0 & -0.1 \\
\hline Hungary & -3.8 & -5.5 & -6.7 & -7.6 & -8.2 & 3.2 & -4.9 & -6.4 & -7.2 & -12.9 & 0.6 & -2.6 & -1.9 & -1.1 & -6.0 \\
\hline Ireland & -0.6 & -0.6 & -0.6 & -0.6 & -0.6 & -9.7 & -5.1 & -13.7 & -16.8 & -18.9 & -9.1 & -4.5 & -13.1 & -16.2 & -18.3 \\
\hline Italy & -11.8 & -11.9 & -11.9 & -11.9 & -11.8 & -17.5 & -11.8 & -7.1 & -9.8 & -13.0 & -5.7 & 0.1 & 3.3 & 1.0 & -2.1 \\
\hline Latvia & -2.5 & -2.5 & -2.5 & -2.7 & -2.9 & -17.4 & -7.0 & -11.1 & -8.4 & 2.6 & -14.9 & -7.9 & -10.8 & -7.4 & -14.5 \\
\hline Lithuania & 88.0 & 88.0 & 88.1 & 88.1 & 88.2 & -12.6 & -2.7 & 5.2 & 5.5 & 5.4 & 75.4 & 78.1 & 74.5 & 76.4 & 77.8 \\
\hline Luxembourg & 0.4 & 0.4 & 0.4 & 4.8 & 3.9 & -39.3 & -30.2 & -27.9 & -23.6 & -21.2 & -39.0 & -29.9 & -27.5 & -18.8 & -17.3 \\
\hline \multicolumn{16}{|l|}{ Malta } \\
\hline Netherlands & 27.0 & 39.2 & 53.2 & 60.8 & 65.4 & 21.0 & 92.9 & 86.6 & 80.3 & 77.1 & 6.1 & -53.7 & -33.5 & -19.5 & -11.7 \\
\hline Poland & -59.4 & -59.2 & -59.0 & -58.8 & -58.7 & -34.7 & -25.5 & -18.6 & -19.2 & -17.7 & 24.7 & 33.7 & 40.4 & 39.7 & 40.9 \\
\hline Portugal & 16.9 & 12.8 & 16.2 & 18.2 & 20.8 & -41.1 & -30.0 & 1.0 & -6.0 & -11.1 & -24.2 & -17.2 & -24.8 & -19.3 & -15.5 \\
\hline Romania & -0.9 & -0.1 & 0.7 & 1.4 & 2.6 & -18.2 & -2.7 & 11.4 & 12.3 & 8.7 & -17.2 & -14.6 & -22.2 & -19.5 & -15.3 \\
\hline Slovakia & -35.5 & -35.4 & -35.3 & -35.0 & -34.8 & -14.4 & 1.4 & 4.3 & 2.2 & 4.0 & 21.1 & 19.6 & 21.3 & 23.5 & 23.3 \\
\hline Slovenia & -15.0 & -14.8 & -14.7 & -14.2 & -13.7 & -10.7 & 1.3 & 1.8 & -1.3 & -7.1 & 4.3 & 2.8 & 5.8 & 4.9 & 0.2 \\
\hline Spain & 14.6 & 20.8 & 23.0 & 23.1 & 23.1 & -15.9 & 3.5 & 24.3 & 19.2 & 15.4 & -1.4 & 1.4 & -12.0 & -4.1 & 1.3 \\
\hline Sweden & -2.3 & -1.8 & -1.3 & -1.2 & -0.5 & 2.8 & 2.7 & -2.7 & 0.7 & 1.9 & -0.5 & -0.9 & -5.0 & -6.3 & -6.0 \\
\hline United Kingdom & 66.4 & 66.3 & 66.4 & 66.5 & 66.7 & -24.1 & -31.6 & -32.7 & -31.5 & -32.4 & 42.4 & 34.8 & 33.7 & 35.0 & 34.2 \\
\hline United States & 1.1 & 1.0 & 0.7 & 0.3 & -0.2 & 0.5 & 4.1 & 7.2 & 7.6 & 7.6 & -4.1 & -5.9 & -8.5 & -7.7 & -7.5 \\
\hline Minimum & -92.1 & -92.1 & -92.1 & -92.1 & -92.0 & -78.3 & -76.2 & -76.6 & -77.0 & -76.5 & -41.1 & -53.9 & -59.7 & -67.0 & -68.6 \\
\hline Average & -0.7 & 0.5 & 0.8 & 1.2 & 1.9 & -13.7 & -2.4 & -0.3 & -1.1 & -1.2 & 0.4 & -0.6 & -1.9 & -0.4 & 0.1 \\
\hline Maximum & 88.0 & 88.0 & 88.1 & 88.1 & 88.2 & 47.6 & 92.9 & 86.6 & 80.3 & 82.5 & 75.4 & 78.1 & 74.5 & 76.4 & 77.8 \\
\hline
\end{tabular}


Table 4 Errors of marine power projections

\begin{tabular}{|c|c|c|c|c|c|c|c|c|c|c|c|c|c|c|c|}
\hline \multirow{2}{*}{$\begin{array}{l}\text { Forecast } \\
\text { horizon (years) }\end{array}$} & \multicolumn{5}{|c|}{ MPE of Capacity (\%) } & \multicolumn{5}{|c|}{ MPE of Generation (\%) } & \multicolumn{5}{|c|}{ MDAPE (\%) } \\
\hline & 1 & 2 & 3 & 4 & 5 & 1 & 2 & 3 & 4 & 5 & 1 & 2 & 3 & 4 & 5 \\
\hline France & 0.0 & 0.0 & 2.2 & 4.9 & 7.8 & 5.0 & 4.9 & 11.6 & 22.6 & 27.9 & -5.0 & -4.9 & -9.4 & -17.7 & -20.0 \\
\hline Portugal & 100.0 & 100.0 & 100.0 & 100.0 & 100.0 & 100.0 & 100.0 & 100.0 & 100.0 & 100.0 & 0.0 & 0.0 & 0.0 & 0.0 & 0.0 \\
\hline United Kingdom & -100 & -100 & -100 & -100 & -100 & -100 & -100 & -100 & -100 & -100 & 0 & 0 & 0 & 0 & 0 \\
\hline Minimum & -100.0 & -100.0 & -100.0 & -100.0 & -100.0 & -100.0 & -100.0 & -100.0 & -100.0 & -100.0 & -5.0 & -4.9 & -9.4 & -17.7 & -20.0 \\
\hline Average & 0.0 & 0.0 & 0.7 & 1.6 & 2.6 & 1.7 & 1.6 & 3.9 & 7.5 & 9.3 & -1.7 & -1.6 & -3.1 & -5.9 & -6.7 \\
\hline Maximum & 100.0 & 100.0 & 100.0 & 100.0 & 100.0 & 100.0 & 100.0 & 100.0 & 100.0 & 100.0 & 0.0 & 0.0 & 0.0 & 0.0 & 0.0 \\
\hline
\end{tabular}

Source: Analysis by authors based on data (EC, 2016a, b; EIA, 2016a, b)

Table 5 Errors of geothermal projections

\begin{tabular}{|c|c|c|c|c|c|c|c|c|c|c|c|c|c|c|c|}
\hline \multirow{2}{*}{$\begin{array}{l}\text { Forecast } \\
\text { horizon (years) }\end{array}$} & \multicolumn{5}{|c|}{ MPE of Capacity (\%) } & \multicolumn{5}{|c|}{ MPE of Generation (\%) } & \multicolumn{5}{|c|}{ MDAPE (\%) } \\
\hline & 1 & 2 & 3 & 4 & 5 & 1 & 2 & 3 & 4 & 5 & 1 & 2 & 3 & 4 & 5 \\
\hline Austria & 0.0 & 0.0 & 0.0 & 0.0 & 0.0 & 100.0 & 100.0 & 100.0 & 100.0 & 100.0 & -100.0 & -100.0 & -100.0 & -100.0 & -100.0 \\
\hline Czech Republic & 0.0 & 0.0 & 0.0 & 25.0 & 40.0 & 0.0 & 0.0 & 0.0 & 25.0 & 40.0 & 0.0 & 0.0 & 0.0 & 0.0 & 0.0 \\
\hline France & 100.0 & 100.0 & 100.0 & 100.0 & 100.0 & 100.0 & 100.0 & 100.0 & 100.0 & 100.0 & 0.0 & 0.0 & 0.0 & 0.0 & 0.0 \\
\hline Germany & 25.0 & 62.5 & 75.0 & 72.9 & 78.3 & -3.6 & 48.2 & 65.5 & 74.1 & 79.3 & 21.4 & 10.7 & 7.1 & -3.0 & -2.4 \\
\hline Greece & 0.0 & 0.0 & 0.0 & 0.0 & 20.0 & 0.0 & 0.0 & 0.0 & 0.0 & 20.0 & 0.0 & 0.0 & 0.0 & 0.0 & 0.0 \\
\hline Hungary & 0.0 & 0.0 & 0.0 & 25.0 & 40.0 & 0.0 & 0.0 & 0.0 & 25.0 & 40.0 & 0.0 & 0.0 & 0.0 & 0.0 & 0.0 \\
\hline Italy & 3.6 & 4.7 & 5.8 & 6.9 & 6.9 & 4.8 & 3.2 & 3.7 & 4.1 & 3.9 & -1.2 & 1.5 & 2.1 & 2.8 & 3.0 \\
\hline Portugal & 0.0 & 0.0 & 0.0 & 3.0 & 6.4 & -17.3 & -19.8 & -9.3 & -8.9 & -8.1 & -17.3 & -19.8 & -17.1 & -11.7 & -6.4 \\
\hline Slovakia & 0.0 & 0.0 & 33.3 & 50.0 & 60.0 & 0.0 & 0.0 & 33.3 & 50.0 & 60.0 & 0.0 & 0.0 & 0.0 & 0.0 & 0.0 \\
\hline United States & 2.3 & 4.2 & 5.2 & 6.9 & 8.3 & 7.6 & 11.0 & 13.2 & 17.8 & 20.5 & -7.4 & -8.7 & -11.5 & -15.5 & -15.7 \\
\hline Minimum & 0.0 & 0.0 & 0.0 & 0.0 & 0.0 & -17.3 & -19.8 & -9.3 & -8.9 & -8.1 & -100.0 & -100.0 & -100.0 & -100.0 & -100.0 \\
\hline Average & 13.1 & 17.1 & 21.9 & 29.0 & 36.0 & 19.2 & 24.3 & 30.6 & 38.7 & 45.6 & -10.5 & -11.6 & -11.9 & -12.7 & -12.2 \\
\hline Maximum & 100.0 & 100.0 & 100.0 & 100.0 & 100.0 & 100.0 & 100.0 & 100.0 & 100.0 & 100.0 & 21.4 & 10.7 & 7.1 & 2.8 & 3.0 \\
\hline
\end{tabular}

Source: Analysis by authors based on data (EC, 2016a, b; EIA, 2016a, b) 
Table 6 Errors of biomass and renewable waste to energy power production projections

\begin{tabular}{|c|c|c|c|c|c|c|c|c|c|c|}
\hline \multirow{2}{*}{$\begin{array}{l}\text { Forecast } \\
\text { horizon (years) }\end{array}$} & \multicolumn{5}{|c|}{ MAPE } & \multicolumn{5}{|c|}{ MPE } \\
\hline & 1 & 2 & 3 & 4 & 5 & 1 & 2 & 3 & 4 & 5 \\
\hline Austria & 5.8 & 5.3 & 4.6 & 4.4 & 5.6 & 5.8 & 5.3 & 4.6 & 4.4 & 5.6 \\
\hline Belgium & 30.6 & 26.5 & 24.7 & 20.3 & 20.2 & -30.6 & -26.5 & -24.7 & -20.3 & -12.3 \\
\hline Bulgaria & 100.0 & 50.9 & 61.2 & 78.2 & 93.8 & -100.0 & -50.9 & -6.7 & 27.3 & 53.1 \\
\hline Cyprus & 14.3 & 9.1 & 6.0 & 13.7 & 17.2 & -14.3 & -9.1 & -6.0 & 4.7 & 10.0 \\
\hline Czech Republic & 10.7 & 8.0 & 5.6 & 4.7 & 4.7 & -10.7 & -8.0 & -5.6 & -4.7 & -4.7 \\
\hline Denmark & 17.9 & 11.7 & 9.6 & 15.5 & 19.0 & -17.9 & -11.7 & -9.6 & 1.2 & 7.6 \\
\hline Estonia & 67.4 & 64.1 & 64.9 & 61.0 & 59.9 & -67.4 & -64.1 & -64.9 & -61.0 & -59.9 \\
\hline Finland & 26.3 & 23.5 & 21.7 & 21.6 & 20.9 & -26.3 & -23.5 & -21.7 & -21.6 & -20.9 \\
\hline France & 22.5 & 20.9 & 24.5 & 34.3 & 44.6 & 22.5 & 20.9 & 24.5 & 34.3 & 44.6 \\
\hline Germany & 4.5 & 6.1 & 10.0 & 11.8 & 13.1 & -4.5 & -6.1 & -10.0 & -11.8 & -13.1 \\
\hline Greece & 33.7 & 28.4 & 27.5 & 25.3 & 40.0 & 33.7 & 28.4 & 27.5 & 25.3 & 40.0 \\
\hline Hungary & 14.9 & 10.5 & 13.8 & 14.0 & 15.0 & -14.9 & -4.4 & 3.9 & 6.5 & 9.0 \\
\hline Ireland & 10.5 & 13.5 & 12.2 & 27.8 & 34.5 & 10.5 & 13.5 & 12.2 & 27.8 & 34.5 \\
\hline Italy & 8.4 & 9.6 & 11.3 & 16.4 & 19.5 & -8.4 & -9.6 & -11.3 & -16.4 & -19.5 \\
\hline Latvia & 9.1 & 19.3 & 19.0 & 21.0 & 19.7 & 9.1 & 19.3 & 6.7 & -1.8 & -4.3 \\
\hline Lithuania & 0.7 & 14.7 & 17.6 & 18.3 & 25.2 & 0.7 & 14.7 & 17.6 & 18.3 & 25.2 \\
\hline Luxembourg & 16.9 & 13.2 & 15.2 & 24.2 & 29.0 & -16.9 & -13.2 & -2.4 & 10.9 & 18.4 \\
\hline Malta & 100 & 100 & 100 & 100 & 100 & 100 & 100 & 100 & 100 & 100 \\
\hline Netherlands & 15.2 & 10.3 & 14.6 & 31.7 & 54.5 & -15.2 & -10.3 & 0.9 & 21.4 & 46.3 \\
\hline Poland & 4.4 & 5.4 & 9.9 & 7.9 & 7.4 & -4.4 & -5.4 & -9.9 & -7.0 & -6.7 \\
\hline Portugal & 8.2 & 8.5 & 6.1 & 5.7 & 6.6 & -8.2 & -8.5 & -5.2 & -2.7 & -0.1 \\
\hline Romania & 39.6 & 69.8 & 79.9 & 84.9 & 87.9 & -39.6 & 30.2 & 53.5 & 65.1 & 72.1 \\
\hline Slovakia & 7.9 & 6.9 & 6.1 & 8.4 & 9.1 & -7.9 & -6.9 & -6.1 & -0.7 & -3.0 \\
\hline Slovenia & 36.7 & 36.3 & 42.7 & 50.6 & 57.8 & 36.7 & 36.3 & 42.7 & 50.6 & 57.8 \\
\hline Spain & 12.5 & 6.8 & 5.2 & 6.7 & 5.7 & 12.5 & 6.8 & 3.8 & 0.1 & 0.4 \\
\hline Sweden & 12.8 & 7.7 & 6.0 & 6.7 & 9.7 & -12.8 & -7.7 & -6.0 & -2.3 & 2.5 \\
\hline United Kingdom & 3.1 & 2.6 & 4.9 & 10.0 & 15.8 & 3.1 & 0.5 & -2.8 & -8.4 & -14.5 \\
\hline United States & 43.4 & 37.0 & 26.7 & 17.8 & 12.3 & -43.4 & -37.0 & -23.2 & -12.5 & 0.9 \\
\hline Minimum & 0.7 & 2.6 & 4.6 & 4.4 & 4.7 & -100.0 & -64.1 & -64.9 & -61.0 & -59.9 \\
\hline Average & 24.2 & 22.4 & 23.3 & 26.5 & 30.3 & -7.5 & -1.0 & 2.9 & 8.1 & 13.2 \\
\hline Maximum & 100.0 & 100.0 & 100.0 & 100.0 & 100.0 & 100.0 & 100.0 & 100.0 & 100.0 & 100.0 \\
\hline
\end{tabular}


Geothermal projections had larger errors than hydro power projections. Geothermal power plant investment is exposed to higher failure risks, a longer payback period, and more complex resource exploration processes ( $\mathrm{Li}$ et al., 2015b). Li et al. (2015b) suggested technology development of enhanced geothermal systems to accelerate geothermal development. The high errors of geothermal production projections were caused by technology failures in some countries. However we suggest future renewables planning should consider the interactions between geothermal and intermittent renewables. Geothermal energy and also hydro power do not have the privilege of priority dispatch, as received by intermittent renewables. Geothermal can act as a balancing power plant so that geothermal capacity factor will be smaller when more variable renewables are connected to the electricity grid, especially in a $100 \%$ renewable energy scenario. Similarly, most countries also cannot reach electricity production targets in biomass and waste to energy. Continuous energy resource supply and the technology reliability should be further investigated to produce more realistic projections for these sources.

\section{Conclusions}

The role of renewable energy to decarbonise global energy system is in doubt after many countries fail to achieve their renewable energy targets. Our study empirically evaluates errors of capacity and generation projections of renewable energy in the EU and US countries. We also develop new indicator called the mean of the difference of absolute percentage error of capacity and absolute percentage error of generation (MDAPE) to show which projections have greater error. Our results for the US are consistent with the findings by Gilbert and Sovacool (2016). We admit that our analysis of the US data has more limitations, such as shorter forecast horizon and we excluded biomass capacity projection analysis to harmonize projection data in EU countries.

Our inter-country comparison may provide benefits for energy-related climate analysis and renewable energy planning globally, in a number of ways. First, we provide a range of uncertainty and errors of renewable energy projections so that policymakers could provide anticipating measures. Second, our findings conclude that solar energy is the most promising renewable energy source to meet emission reduction target in the electricity sector, especially if its price continuously declines in the long-term. Third, we found that renewable projections mostly overestimated the capacity factor, except for hydro power. Last, we suggest other countries should learn the implementation policies and experiences of the successful countries.

Our findings will help countries setting ambitious renewable energy targets by identifying that most renewable energy planning has overestimated the capacity factors. For example, IEA and NEA (2015) used $10 \%$ as the minimum capacity factor of solar energy while we found that the capacity factor could reach $0 \%$, as shown in Table 7. Overconfidence on renewable energy generation may deteriorate electricity system reliability, as recently occurred in South Australia (Lucas, 2017). Renewable energy types with wide range of capacity factors, e.g. geothermal, call for more comprehensive assessments for technology, site selections and, most importantly, failure anticipation strategies. Finally, we suggest further studies to analyse renewable energy projections in developing countries like China and India to improve our findings.

\section{Conflict of Interest Statement}

The authors declare that the research was conducted in the absence of any commercial or financial relationships that could be construed as a potential conflict of interest. 


\section{Funding}

The authors acknowledge the funding support from the Indonesia Endowment Fund for Education (LPDP), Ministry of Finance - the Republic of Indonesia (Grant no: 20141122092191); and the research grant from the School of Earth and Environmental Sciences at the University of Queensland.

Table 7 Capacity factors of renewable energy in the analysed countries

\begin{tabular}{llrrrrr}
\hline Renewables types & CF & 2010 & 2011 & 2012 & 2013 & 2014 \\
\hline Hydro & Min & 13.4 & 11.4 & 11.7 & 11.7 & 10.0 \\
& Average & 29.8 & 26.4 & 27.7 & 27.9 & 29.7 \\
Geothermal & Max & 51.9 & 68.5 & 60.2 & 53.3 & 61.6 \\
& Min & 11.4 & 0.0 & 0.0 & 0.0 & 0.0 \\
Solar & Average & 65.0 & 53.7 & 42.2 & 35.9 & 35.0 \\
& Max & 99.5 & 98.9 & 94.4 & 95.1 & 99.3 \\
Tide, Wave and Ocean & Min & 0.0 & 0.1 & 2.2 & 5.7 & 3.0 \\
& Average & 9.1 & 10.1 & 10.6 & 11.7 & 12.6 \\
& Max & 22.0 & 19.5 & 21.5 & 21.5 & 26.9 \\
Wind & 22.6 & 11.4 & 15.2 & 19.7 & 0.0 \\
& Average & 22.7 & 17.1 & 18.5 & 21.3 & 10.2 \\
& Max & 22.8 & 22.7 & 21.8 & 22.8 & 22.9 \\
& Min & 4.3 & 9.7 & 11.4 & 11.4 & 11.4 \\
& Average & 19.8 & 22.4 & 22.1 & 23.0 & 23.0 \\
Source: Analysis by authors based on data $($ EC, $2016, \mathrm{~b} ;$ & EIA, $2016 \mathrm{~b})$
\end{tabular}

Source: Analysis by authors based on data (EC, 2016a, b; EIA, 2016a, b)

\section{References}

ANRE, 2014. Strategic Energy Plan, Provisional Translation ed. Agency for Natural Resources and Energy (ANRE) - the Government of Japan.

Ascher, W., 1978. Forecasting : an appraisal for policy-makers and planners / William Ascher. Baltimore : Johns Hopkins University Press, Baltimore.

Bell, D., Gray, T., Haggett, C., Swaffield, J., 2013. Re-visiting the 'social gap': public opinion and relations of power in the local politics of wind energy. Environmental Politics 22, 115-135.

Bhattacharya, M., Paramati, S.R., Ozturk, I., Bhattacharya, S., 2016. The effect of renewable energy consumption on economic growth: Evidence from top 38 countries. Applied Energy 162, 733-741.

Bhattacharyya, S.C., Timilsina, G.R., 2010. A review of energy system models. International Journal of Energy Sector Management 4, 494-518.

Brouwer, A.S., Van Den Broek, M., Seebregts, A., Faaij, A., 2014. Impacts of large-scale Intermittent Renewable Energy Sources on electricity systems, and how these can be modeled. Renewable and Sustainable Energy Reviews 33, 443-466.

Byrnes, L., Brown, C., Foster, J., Wagner, L.D., 2013. Australian renewable energy policy: Barriers and challenges. Renewable Energy 60, 711-721.

Capellaro, M., 2016. Prediction of site specific wind energy value factors. Renewable Energy 87, 430436.

Carley, S., 2009. State renewable energy electricity policies: An empirical evaluation of effectiveness. Energy policy 37, 3071-3081. 
Dalton, G., 2009. Non-technical barriers to wave energy in Europe, Proceedings of the 8th European Wave and Tidal Energy Conference, Uppsala, Sweden, 2009, pp. 64-71.

Dannenberg, A., Mennel, T., Moslener, U., 2008. What does Europe pay for clean energy?-Review of macroeconomic simulation studies. Energy Policy 36, 1318-1330.

Delucchi, M.A., Jacobson, M.Z., 2011. Providing all global energy with wind, water, and solar power, Part II: Reliability, system and transmission costs, and policies. Energy policy 39, 1170-1190.

Dulal, H.B., Shah, K.U., Sapkota, C., Uma, G., Kandel, B.R., 2013. Renewable energy diffusion in Asia: Can it happen without government support? Energy Policy 59, 301-311.

EC, 2016a. EU Energy Statistic Website. European Commission (EC).

EC, 2016b. National action plans. European Commission (EC).

EIA, 2016a. Annual Energy Outlook 2002 - 2014. Energy Information Administration (EIA), Washington.

EIA, 2016b. Annual Energy Review website. Energy Information Administration (EIA), Washington.

Gilbert, A.Q., Sovacool, B.K., 2016. Looking the wrong way: Bias, renewable electricity, and energy modelling in the United States. Energy 94, 533-541.

He, G., Kammen, D.M., 2016. Where, when and how much solar is available? A provincial-scale solar resource assessment for China. Renewable Energy 85, 74-82.

Heard, B., Brook, B., Wigley, T., Bradshaw, C., 2017. Burden of proof: A comprehensive review of the feasibility of 100\% renewable-electricity systems. Renewable and Sustainable Energy Reviews 76, 1122-1133.

IEA, NEA, 2015. Projected Costs of Generating Electricity - 2015 Edition. International Energy Agency (IEA) and Nuclear Energy Agency (NEA), Paris.

Jacobson, M.Z., Delucchi, M.A., 2011. Providing all global energy with wind, water, and solar power, Part I: Technologies, energy resources, quantities and areas of infrastructure, and materials. Energy policy 39, 1154-1169.

Jefferson, M., 2014. Closing the gap between energy research and modelling, the social sciences, and modern realities. Energy Research \& Social Science 4, 42-52.

Li, F.G., Trutnevyte, E., Strachan, N., 2015a. A review of socio-technical energy transition (STET) models. Technological Forecasting and Social Change 100, 290-305.

Li, K., Bian, H., Liu, C., Zhang, D., Yang, Y., 2015b. Comparison of geothermal with solar and wind power generation systems. Renewable and Sustainable Energy Reviews 42, 1464-1474.

Linderoth, H., 2002. Forecast errors in IEA-countries' energy consumption. Energy Policy 30, 53-61.

Lucas, A., 2017. Confected conflict in the wake of the South Australian blackout: Diversionary strategies and policy failure in Australia's energy sector. Energy Research \& Social Science 29, 149159.

Luderer, G., Krey, V., Calvin, K., Merrick, J., Mima, S., Pietzcker, R., Van Vliet, J., Wada, K., 2014. The role of renewable energy in climate stabilization: results from the EMF27 scenarios. Climatic change 123, 427-441.

MacGillivray, A., Jeffrey, H., Hanmer, C., Magagna, D., Raventos, A., Badcock-Broe, A., 2013. Ocean energy technology: gaps and barriers. International Journal of Marine Energy 11, 20.

Magagna, D., Uihlein, A., 2015. Ocean energy development in Europe: Current status and future perspectives. International Journal of Marine Energy 11, 84-104.

Marques, A.C., Fuinhas, J.A., Manso, J.P., 2011. A quantile approach to identify factors promoting renewable energy in European countries. Environmental and Resource Economics 49, 351-366.

Masini, A., Menichetti, E., 2012. The impact of behavioural factors in the renewable energy investment decision making process: Conceptual framework and empirical findings. Energy Policy 40, 28-38.

MEECC, 2010. National Renewable Energy Action Plan in the Scope of Directive 2009/28/EC. Ministry of Environment Energy \& Climate Change (MEECC), Government of Greece.

Metayer, M., Breyer, C., Fell, H.-J., 2015. The projections for the future and quality in the past of the World Energy Outlook for solar PV and other renewable energy technologies, 31st European Photovoltaic Solar Energy Conference and Exhibition.

METI, 2015. Long -term Energy Supply and Demand Outlook, Provisional Translation ed. Ministry of Economy, Trade and Industry (METI) - the Government of Japan.

MNRE, 2011. Strategic Plan for New and Renewable Energy Sector for the Period 2011-17. Ministry of New and Renewable Energy(MNRE) - Government of India. 
MNRE, 2017. Programme/ Scheme wise Physical Progress in 2017-18 \& cumulative upto the month of June, 2017. Ministry of New and Renewable Energy(MNRE) - Government of India.

Moch, J., 2014. Table: What Are China's National Climate and Energy Targets?. ChinaFAQs - The Network for Climate and Energy Information, in: Institute, W.R. (Ed.).

O’Neill, B.C., Desai, M., 2005. Accuracy of past projections of US energy consumption. Energy Policy 33, 979-993.

Park, J., Craggs, R., Shilton, A., 2013. Enhancing biomass energy yield from pilot-scale high rate algal ponds with recycling. Water research $47,4422-4432$.

Pindyck, R.S., 2015. The use and misuse of models for climate policy. National Bureau of Economic Research.

REN21, 2015. Renewables 2015 Global Status Report. Renewable Energy Policy Network for the 21 Century (REN21) Secretariat, Paris.

REN21, 2017. Renewables 2017 Global Status Report. Renewable Energy Policy Network for the 21 Century (REN21) Secretariat, Paris.

Robinson, S.A., Rai, V., 2015. Determinants of spatio-temporal patterns of energy technology adoption: An agent-based modeling approach. Applied Energy 151, 273-284.

Sanders, D.R., Manfredo, M.R., Boris, K., 2009. Evaluating information in multiple horizon forecasts: The DOE's energy price forecasts. Energy economics 31, 189-196.

Schwanitz, V.J., 2013. Evaluating integrated assessment models of global climate change. Environmental modelling \& software 50, 120-131.

Shrimali, G., Lynes, M., Indvik, J., 2015. Wind energy deployment in the US: An empirical analysis of the role of federal and state policies. Renewable and Sustainable Energy Reviews 43, 796-806.

Sohn, I., 2007. Long-term energy projections: What lessons have we learned? Energy policy 35, 45744584.

Szabó, S., Waldau, A.J., Szabó, M., Monforti-Ferrario, F., Szabó, L., Ossenbrink, H., 2014. European renewable government policies versus model predictions. Energy Strategy Reviews 2, 257-264.

Tang, A., 2013. Leveraging Policy for Renewable Energy Development in Industrialized Countries and Emerging Markets. Columbia University.

Tasri, A., Susilawati, A., 2014. Selection among renewable energy alternatives based on a fuzzy analytic hierarchy process in Indonesia. Sustainable Energy Technologies and Assessments 7, 3444.

Taylor, P.G., Upham, P., McDowall, W., Christopherson, D., 2014. Energy model, boundary object and societal lens: 35 years of the MARKAL model in the UK. Energy Research \& Social Science 4, 32 41.

Trutnevyte, E., McDowall, W., Tomei, J., Keppo, I., 2016. Energy scenario choices: Insights from a retrospective review of UK energy futures. Renewable and Sustainable Energy Reviews 55, 326337.

Uri, V., Aosaar, J., Varik, M., Becker, H., Kukumägi, M., Ligi, K., Pärn, L., Kanal, A., 2015. Biomass resource and environmental effects of Norway spruce (Picea abies) stump harvesting: an Estonian case study. Forest Ecology and Management 335, 207-215.

Wang, F., Yin, H., Li, S., 2010. China's renewable energy policy: commitments and challenges. Energy Policy 38, 1872-1878.

Weijermars, R., Taylor, P., Bahn, O., Das, S.R., Wei, Y.-M., 2012. Review of models and actors in energy mix optimization-can leader visions and decisions align with optimum model strategies for our future energy systems? Energy Strategy Reviews 1, 5-18.

Winebrake, J.J., Sakva, D., 2006. An evaluation of errors in US energy forecasts: 1982-2003. Energy policy 34, 3475-3483.

Yan, R., Saha, T.K., 2012. Voltage variation sensitivity analysis for unbalanced distribution networks due to photovoltaic power fluctuations. IEEE Transactions on Power Systems 27, 1078-1089.

Yi, H., Feiock, R.C., 2014. Renewable energy politics: policy typologies, policy tools, and state deployment of renewables. Policy Studies Journal 42, 391-415.

Zyadin, A., Halder, P., Kähkönen, T., Puhakka, A., 2014. Challenges to renewable energy: A bulletin of perceptions from international academic arena. Renewable Energy 69, 82-88. 